\title{
Method of detecting minute quantities of opium, in solution
}

\section{R. Hare M.D.}

To cite this article: R. Hare M.D. (1827) Method of detecting minute quantities of opium, in solution, Philosophical Magazine Series 2, 2:9, 233-233, DOI: $10.1080 / 14786442708675661$

To link to this article: http://dx.doi.org/10.1080/14786442708675661

曲 Published online: 10 Jul 2009.

Submit your article to this journal ¿

Џll Article views: 2

Q View related articles ¿ 
METHOD OF DETECTING MINUTE QUANTITIFS OF OPIUM, IN SOLUTION : BY R. HARE, M.D.

Through the discoveries of Sertuerner, it is now well known that opium contains an alkaline substance called morphia, to which it owes its efficacy in promoting sleep and relieving pain: also, that this alkali is naturally in union with an acid called meconic, which produces a striking red colour with solutions of red oxide of iron. Nevertheless, this property has not been proposed as a means of detecting opium; which has probably arisen from the circumstance that the meconate of iron does not precipitate. I have, however, contrived a method by which a quantity of opium not exceeding that contained in ten drops of laudanum may be detected in a halfgallon of water.

My process is founded on the property which meconic acid has of precipitating with lead. Hence, by adding a few drops of acetate of lead to any infusion, contaning any quantity of the drug in question, not more minute than the proportion above mentioned, an observable quantity of the meconate of lead falls down. The precipitation, where the quantity is small, may require from six to twelve hours, and may be facilitated by a very gentle stirring with a glass rod to detach the flocks from the sides of the recipient, which should be conical, so as to concentrate them during their descent. The meconate being thus collected at the bottom of the vessel, let about thirty drops of sulphuric acid be poured down on it by means of a glass tube. Let this be followed by as much of the red sulphate of iron. The sulphuric acid liberates the meconic acid, and thus enables it to produce, with the iron, the appropriate colour which demonstrates the presence of that acid, and consequently of opium.

EASY MODE OF OBTAINING MECONIC ACID: BY R. HARE, M.D.

If to an aqueous infusion of opium we add subacetate of lead, a copious precipitation of meconate of lead ensues. This being collected by a filter, and exposed to sulphuretted hydrogen, meconic acid is liberated. The solution is of a reddish amber colour, and furnishes by evaporation crystals of the same hue. A very small quantity produces a very striking effect in reddening solutions of peroxide of iron.

Instead of sulphuretted hydrogen, sulphuric acid may be used to liberate the meconic acid. The presence of the former, in excess, does not seem to interfere with the power of reddening ferruginous solutions; but any excess of sulphuric acid may be removed by whiting, which is not acted upon sensibly by the meconic acid. Yet the acid procured in this way did not crystallize so handsomely, or with so much facility, as that obtained by sulphuretted hydrogen.

METHOD OF PREPARING DENARCOTIZED LAUdANUM: BY

R. HARE, M.D.

Agreeably to the observations of the French chemists and physicians, the unpleasant effects of opium reside in a principle called New Series. Vol. 2. No. 9. Sept. 1827. $2 \mathrm{H}$ narco- 